so shading off the most intense inflammation until we come to the healthy parts; thus, in a simple incised wound, where the parts have been brought together, and where adhesion is going on, we see, at the edges, much injection, dying away through a blush to the natural colour of the skin; a suppurative inflammation is surrounded by an adhesive inflammation, dying away as the last; and a gangrenous inflammation is terminated by a suppurative at the place where Nature makes the effort to throw off the dead parts; this is circumscribed by the adhesive, in which there is hardness and effusion of lymph, and, further still, we see the injection, blush, \&c. Having this knowledge, we find that in the case in question we have only to excite in the vagina such a degree of inflammation that the ad. hesive process shall reach through the vaginal parietes to the cellular tissue which connects the vagina to the surrounding parts; and this is what has been done, although, it wonld appear, unintentionally, in the various cases reconded; thus, in the use of escharotics, and actual cautery, the gangrenous inflammation has been excited, while by Dr. Marshall Hall's plan the suppurative has been produced. Now, we further know that when inflammations terminate (in whatever way) they all, except the gangrenous, pass through the subordinate stages, until that which was the most intense, after having come to the slight blush, returns to the natural state. And this brings me to the case mentioned by $\mathrm{Dr}$. Marshall Hall (Lancet, May 18, p. 316) where, some time after his operation, the uterus was (as I understand) reprotruded. I should look upon the want of success in this case as dependent upon the inflammation having begun to contract its spbere when this accident happened, so that the adhesive inflammation having left the parts where it was required, and the solidification of the parts not being completed, the vagina was ineffectually returned to its place. As the cicatrix in the vagina would, however, necessarily contract, I think this case, although solitary, is sufficient to show that the cure does not depend upon the contraction of the vagina.

I have already remarked that $I$ have entertained these views for some years, but, as frequently happens when we wish to try an experiment, I had not been able to meet with a case under my own care, when, at last, I obtained one in my practice at the Farringdon Dispensary. I then began to consider how I should sei up a process of inflammation in the vagina sufficiently intense for the adhesive inflammation to reach through the walls far enough to carry my intentions into effect, in such a way, how. ever, that I might not occasion inflammation of the uterus by continuity, or of the peritoneum by contiguity, and which should cause the least degree of suffering to the patient. I, therefore, tried a very large globe pessary. After using this for some time without success, I had determined to see what might be done by some deep scarifications in the vagina, when, unfortunately, the patient slipped through my fingers, by breaking her leg, when she was taken to the hospital, which, I believe, in that neighbourhood, generally means st. Bartholomew's. I think, upon the whole, that perbaps the best means which could occur as a cure would be the contraction of a severe gonorrhoea on the part of the patient. And here I trust my professional brethren will not laugh at me, for $I$ assure them that $I$ speak not only in earnest, but in all modesty, for I hold that gonorrhoea is not contracted as a consequence of a contaminated sexual intercourse. I am the more inclined to think that gonorrhoea (provided it were sufficiently severe) might be a good means of cure from what occurs in the male when under that disease, namely, the production of chordee. In the meantime, I remain, Sir your very obedient servant,

John Chippendale.

10, Bedford-street, Bedford-square, June 10, 1839.

\section{TREATMENT OF HYDROPHOBIA.}

\section{To the Editor of THE LANCET.}

SIR:-It is an old axiom that desperate diseases warrant the use of desperate remedies; I am willing to subscribe to this doctrine, but I cannot, therefore, give my assent to the practice of combatting disorders usually fatal with weapons equally so; or, in other words, pitting one poison against another, that the patient may have the pleasure of dying secundem artem, rather than by natural means! I am induced to make these remarks from having observed an interesting case of hydrophobia that was recorded in THE LanceT a short time since, by Mr. Cripps, of Liverpool, where the patient, in my opinion, died of the remedy rather than the disease. It is referred to in the last week's LANCET, and evidence adduced tending to infer that the case terminated in typhus; this inference $I$ am disposed to doubt, for reasons to be alleged, and as no one has hitherto offered any comments thereon, I beg permission, through the medium of your Journal, to do so, and at the same time to enter my professional protest against the abuse of powerful and dangerous remedies on purely speculative grounds. Hydrophobia has rarely, if ever, been cured; it is allowed to proceed from a specific poison, operating on the nervous system alone, and, through its irritation thereon, producing violent spasms, more 
nearly resembling tetanus than any other complaint. I should like to know with what vitw the croton oil was given. in such a case, for $I$ confess $I$ do not see its indication; but, granting the propriety of the remedy, how does Mr. Cripps justify its exhibition in such an enormous quantity? I have fre. quently seen most violent symptoms pro. duced by the administration of a single drop of this medicine, from its highly acrid and irritating effects upon the mucous membrane of the intestines. What, then, are we to expect where twenty times this quantity is given, in a short space of time, to a patient whose nervous energy is already greatly exhausted? Why, Sir, just what every intelligent practitioner would anticipate, and what I have, no doubt, was the fact in this instance, riz., inflammation of the lining membrane of the whole intestinal tube. I am borne out in this opinion by the symptoms detailed in the last week's Lancer ; and hence Mr. Cripps may receive a solution to his surprise at the patient's so rapidly sinking from typhoid symptoms, when he had apparently overcome the original complaint. I find no fault with the hydrocyanic acid being given, but $I$ must be allowed to object to the dose, which, according to the narrator's account, had nearly proved fatal. My only motive in making these observations is to caution the junior branches of the profession against rashly administering dangerous remedies, whore others, compatible with life, may be used with an equal chance of success; but where it is desirable to administer such, why not do it through the same channel that has imbibed the poison, viz., the vascular system? I confess that were a case of hydrophobia to fall under my treatment, I should blister the whole spinal surface, and through that medium introduce my antidote; at all events $I$ should consider it the safest and most direct means of allaying nervous irritation. I am, Sir, yours, \&c. \&c.

Windsor, June 1, 1839. William Moss.

\section{THE LA N CET.}

London, Saturday, June 15, 1839.

WHEN we last referred to the Royal College of Surgeons of Dublin, it was to denounce its constitution, and to hold up to execration the narrow, monopolising acts which excluded from its privileges, and from all offices of trust in Ireland, 2400 out of 3000 educated physicians and surgeons. We are glad now to be able to speak in other terms of the Dablin College of Surgeons ; that College has placed itself at the head of the movement party in Ireland; it has at last perceived that the interests of its members cannot be separated from those of the whole profession; or, at least, that they cannot be successfully sustained against the threatening army of apothecary-druggists, the Poor-Law Commissioners, the progress of public opinion, and 2400 intelligent and resolute Irish practitioners. Some persons, we are well aware, look upon the course of conduct pursued by the Dublin College with suspicion; they scrutinize its motives closely, and ask, " Can any good come from " an evil source? Can a corrupt curporation " be transformed into a healthy, free, bene"ficial institution?" The metamorphosis is, no doubt, extraordinary; but the deformed may become transformed, and corruption may put on incorruption, if the original body first die-if the soul of egotism and selfishness exhale, and allow the elements to recombine under the vivifying influence of public virtue. The College of Surgeons has expressly declared its desire to constitute, in conjunction with its brethren of other Colleges, an Irish Faculty of Medicine-one great section of the tripartite National Faculty of Medicine. Its leading officers have expressed this decision with frankness, and it wonld ill become medical reformers to suspect a lurking insincerity so long as the acts of the College keep pace with the liberal declarations of its members.

Let us not, however, be led away by liberal sounds, but proceed to exam the substantial nature of some of the resolutions. How is the new College to be constituted? It is proposed that physicians and surgeons should receive the same elementary education, and should be members of one College. It was moved by Dr. TuoniLl, " that at the "first formation of the College, all persons " holding degrees or diplomas in medicine or " surgery from any of the Colleges or Unirer"sities at present legally authorised to " grant the same, who have been fire years 